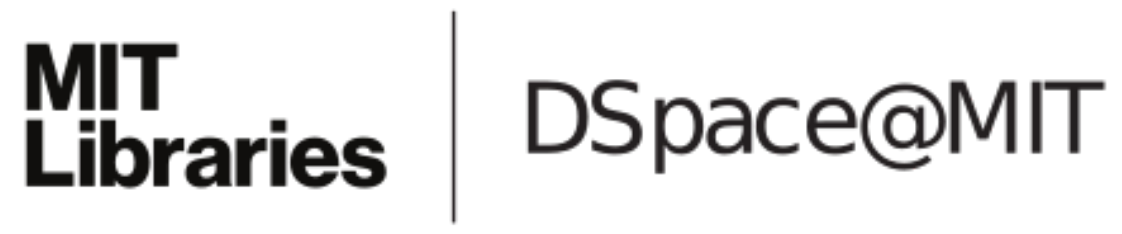

\author{
MIT Open Access Articles
}

A numerical study of the effect of wetland shape and
inlet-outlet configuration on wetland performance

The MIT Faculty has made this article openly available. Please share how this access benefits you. Your story matters.

As Published: 10.1016/J.ECOLENG.2017.04.062

Publisher: Elsevier BV

Persistent URL: https://hdl.handle.net/1721.1/135771

Version: Author's final manuscript: final author's manuscript post peer review, without publisher's formatting or copy editing

Terms of use: Creative Commons Attribution-NonCommercial-NoDerivs License 


\section{A numerical study of the effect of wetland shape and inlet- 2 outlet configuration on wetland performance}

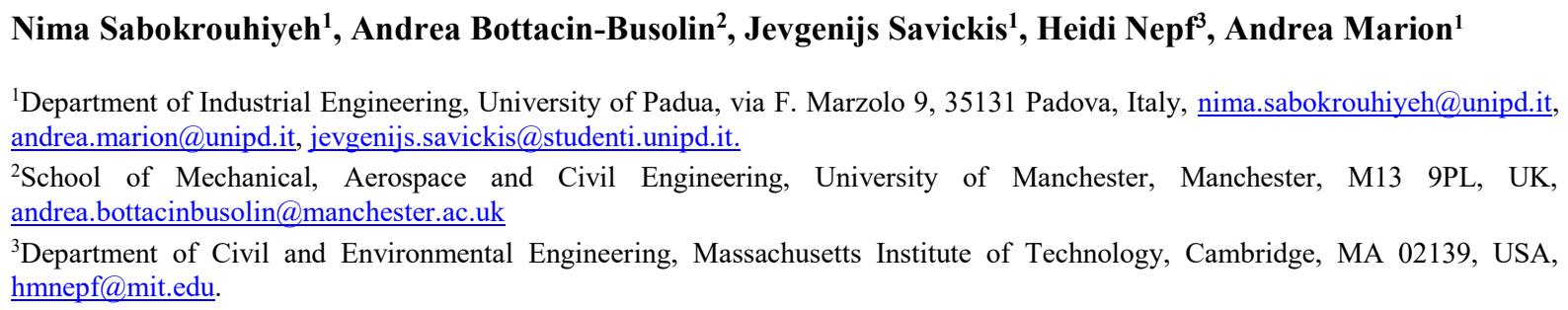

Abstract. The hydraulic efficiency of wetlands for wastewater treatment was investigated as a function of wetland shape and vegetation density using a 2D depth-averaged numerical model. First, the numerical model was calibrated and validated against field data and then was applied to 8 hypothetical wetlands of rectangular and elliptical shape and different aspect ratio (i.e. $1: 1$ to $4: 1$ ). The vegetation density was varied from 0 to $1000 \mathrm{stems} / \mathrm{m}^{2}$. The effect of inlet-outlet configuration was analyzed by simulating the hydraulic response of wetlands with different alignment of the flow inlet and outlet and wetlands with multiple inlets. The resulting Residence Time Distributions (RTDs) were derived from numerical simulations of the flow field and the temporal evolution of the outlet concentration of a passive tracer injected at the inlet. The simulated velocity field demonstrated that wetland shape can have significant impact on the size of dead zone areas, which is also reflected in the RTD. Efficiency metrics associated with detention time and degree of mixing improved for an elliptical shape compared to a rectangular shape. An ellipse shape improved the wetland performance by reducing the area of dead zones at the corners, and thereby increasing the effective wetland volume contributing to the treatment process. Configurations in which inlet and outlet were located at opposite corners of the wetland, and wetlands with multiple inlets produced smaller dead zones, which reduced the variance of the RTD. The simulation results also revealed an interesting threshold behavior with regard to stem density. For stem density above $300 \mathrm{stems} / \mathrm{m}^{2}$, which is typical of treatment wetlands, the model predictions were not sensitive to the exact value of stem density selected, which simplifies the parameterization of models. This quantitative analysis of the effect of wetland shape, inlet-outlet configuration and vegetation density can help engineers to achieve more efficient and cost-effective design solutions for wastewater treatment wetlands.

Keywords: Constructed wetlands, Shallow water model, Detention time, Dispersion, Vegetation, Design.

\section{Introduction}

Free water surface constructed wetlands (FWS CWs) can remove a variety of contaminants from municipal wastewater (Cameron et al., 2003; Kipasika et al., 2014), storm water al., 2015), agricultural wastewater (Maucieri et al., 2014; Vymazal and Březinová, 2015), 
road runoff (Gill et al., 2014), woodwaste leachate (Tao et al., 2006), and landfill leachate

42 (Yang and Tsai, 2011). The effectiveness of constructed wetlands in removing different forms of contaminants is well documented (Vymazal, 2013). For example, phosphorus removal has been documented in over 250 FWS wetlands, for a wide range of inflow concentrations, from below $20 \mu \mathrm{g} / \mathrm{L}$ to over $100 \mathrm{mg} / \mathrm{L}$ (Kadlec and Wallace, 2009). Hsueh et al. (2014) reported 85\% removal of TN (total nitrogen) in a subtropical free water surface CW in Taiwan with retention time of 3.7 days. Batty and Younger (2002) found that where dissolved iron concentrations in wetland waters were at or below $1 \mathrm{mg} / \mathrm{L}$, direct uptake of iron by plants could account for $100 \%$ of iron removal. Kotti et al. (2010) investigated the performance of five FWS CWs and observed average removal values of $77.5 \%, 67.9 \%$, $60.4 \%, 53.9 \%, 56.0 \%$ and $51.7 \%$ for BOD, COD, TKN, ammonia (NH4-N), ortho-phosphate (PO4-P) and total phosphorus (TP), respectively. Although CWs have the potential to improve water quality significantly, there is a large variability in their hydraulic efficiency and removal rates (Persson et al., 1999). Wetland characteristics including wetland shape, inlet-outlet configuration, vegetation coverage and water depths affect the hydraulics of CWs, which directly influences removal rates. Designing a constructed wetland to achieve a certain performance level requires optimization of these wetland properties (Marion et al., 2014).

The hydraulic design of a wetland has two main requirements: (1) the resulting hydraulic residence time (HRT) must be sufficiently long to allow for the natural treatment processes to remove the contaminants (Thackston et al., 1987); (2) the wetland must provide a condition close to plug flow, for which dispersion is minimum, so that all water parcels experience a residence time close to the HRT (Holland et al., 2004; Persson et al., 1999). Hydraulic retention time (HRT) is the average amount of time a passive solute spends in a wetland system. A longer retention time provides more time for biochemical reactions to occur in the wetland, and thus increases pollutant removal (Kadlec and Wallace, 2009). Toet et al. (2005) evaluated the pollutant removal in a FWS under four hydraulic retention times from 0.3 to 9.3 days and found that increasing HRT led to considerable increase in the removal of total nitrogen, ammonium, and nitrates. A minimum HRT of 4 days was found to be necessary for a nitrogen removal efficiency of approximately $45 \%$, corresponding to an annual mass loading rate of $150 \mathrm{gr} \mathrm{m}^{-2} \mathrm{yr}^{-1}$. The hydraulic efficiency of a wetland is characterized in terms of two non-dimensional parameters. The first is the dimensionless retention time, defined as $e=t_{m} / t_{n}$, in which $t_{m}$ is the observed mean residence time, and $t_{n}=V / Q$ is the nominal residence time, in which $V$ is the volume of the wetland and $Q$ is the input discharge 
rate (Thackston et al., 1987). The optimum residence time would be achieved when the ratio approaches unity $\left(t_{m}=t_{n}\right)$, which implies that there are no dead zones in the wetland, and the whole wetland volume actively contributes to the treatment processes. The second design criterion describes the departure from plug flow due to dispersion processes. Dispersion arises from inlet and outlet effects, vegetation distribution patterns, bottom topography, wind effects and shear stresses from sides. Dispersion makes some parcels of water exit before and after the nominal resistance time $\left(t_{n}\right)$. Because the biochemical reactions impacting pollutant removal are mostly first-order reactions, there is a greater disbenefit to pollutant removal for parcels of water leaving before $t_{n}$ compared to the benefit for parcels leaving after $t_{n}$, so that any dispersion, which creates a greater variance in individual residence times, will diminish the overall pollutant removal.

Wetland shape can significantly affect both dead zones (Kotti et al., 2010) and dispersion (Holland et al., 2004) in wetlands. Thackston (1987) found that distinct dead zones and mixed zones are present in every wetland, and their size and location varies as a function of wetland shape and inlet-outlet positions. Persson (1999) studied 13 rectangular ponds of different aspect ratio (i.e. $L: W$, length-to-width ratio) and concluded that higher aspect ratios decrease the dead-zone area by as much as $20 \%$. Sabokrouhiyeh et al. (2016) showed that a low aspect ratio in combination with sparse vegetation coverage causes more dispersion and larger dead zones in rectangular wetlands. Despite the importance of the subject, only a few studies have investigated the effects of wetland shape on the behavior of inert tracers and on the performance of ponds and wetlands for pollutant reduction (Kadlec and Wallace, 2009). Instead, the focus of most published studies has been on the effects on wetlands hydraulics as a function of aspect ratio (Jenkins and Greenway, 2005; Persson et al., 1999; Su et al., 2009; Thackston et al., 1987). It has been shown that long, narrow wetlands (high aspect ratios) give rise to plug-flow conditions and consequently provide higher hydraulic efficiencies than wider (low aspect ratio) wetlands. However, narrow, long wetlands can produce operational problems associated with high surface water slopes at high hydraulic loading rates (Koskiaho, 2003). For example, Reed et al. (1995) reported that a FWS wetland constructed with aspect ratio of 20:1 experienced overflow due to a dramatic head drop. In addition, construction costs are higher for a narrow wetland, because such a design requires a larger berm length per wetland area (Kadlec and Wallace, 2009). Therefore, there is a need to further investigate other wetland geometries, and other factors, such as inlet-outlet geometry, that may positively impact wetland performance. 
107 The flow pattern generated by the inlet impacts the distribution of flow within the wetland

108 (Somes et al., 1999). An appropriate design of inlet-outlet configuration increases HRT and 109 enhances the flow uniformity (Persson et al., 1999; Su et al., 2009; Suliman et al., 2006). Su

110 et al. (2009) showed the highest wetland hydraulic performance (greatest pollutant removal)

111 was obtained with a uniform inlet and an outlet located at mid-width. They also found that

112 the use of subsurface berms could be an efficient way to improve the wetland performance.

113 Numerical simulation of a pond with low aspect ratio $(\mathrm{L}: \mathrm{W}=2: 1)$ indicated that changing a

114 single inlet to multiple inlets increased wetland effective volume ratio from 60 to $75 \%$ (Su et

115 al., 2009). For a higher aspect ratio $(L: W=5: 1)$, having the outlet placed close to the inlet

116 produced an effective volume ratio of just $40 \%$, compared to nearly $80 \%$ if the outlet was

117 placed at the opposite end of the pond (Persson et al., 1999). Numerical simulations by

118 Koskiaho (2003) showed that the number of inlets and their position do not significantly

119 affect flow patterns in wetlands of high aspect ratio, but did have an impact for aspect ratios 120 less than $4: 1$.

121 The present study analyzed the impact of different wetland design parameters on wetland 122 efficiency (degree of pollutant removal), considering different wetland shapes, vegetation 123 densities and inlet-outlet configurations. The analysis used 2-D depth-averaged simulations

124 of flow hydrodynamics and mass transport. The objective of the study was to provide 125 quantitative understanding of how different performance metrics are affected by wetland 126 geometry and vegetation density, which can help engineers to achieve more efficient and 127 cost-effective design solutions.

\section{Theoretical background}

\subsection{Two-Dimensional numerical wetland model}

130 A 2-dimensional numerical model of a wetland was developed to simulate the velocity field 131 and the transport of a dissolved tracer under steady conditions. The hydrodynamic model solved the shallow-water equations and a solute transport model solved the depth-averaged advection-diffusion equations.

\subsubsection{Hydrodynamic model}

135 Under the assumption of hydrostatic pressure, steady flow, and negligible wind and Coriolis

136 forces, the depth-averaged velocity field and water depth can be described by the following 137 equations (Wu, 2007). 


$$
\frac{\partial\left(h U_{x}\right)}{\partial x}+\frac{\partial\left(h U_{y}\right)}{\partial y}=0
$$

$$
\begin{aligned}
& \frac{\partial\left(h U_{x}^{2}\right)}{\partial x}+\frac{\partial\left(h U_{x} U_{y}\right)}{\partial y}=-g h \frac{\partial\left(z_{S}\right)}{\partial x}-\frac{\tau_{b x}}{\rho}-\frac{\tau_{v x}}{\rho} \\
& \frac{\partial\left(h U_{x} U_{y}\right)}{\partial x}+\frac{\partial\left(h U_{y}^{2}\right)}{\partial y}=-g h \frac{\partial\left(z_{s}\right)}{\partial y}-\frac{\tau_{b y}}{\rho}-\frac{\tau_{v y}}{\rho}
\end{aligned}
$$

141 Here, $U_{x}$ and $U_{y}$ are the velocity components along the $x$ and $y$ directions; $h$ is the water

142 depth; $z_{s}$ is the water surface elevation; $\rho$ is the water density; $\tau_{b x}$ and $\tau_{b y}$ are the bed shear

143 stresses in $\mathrm{x}$ and $\mathrm{y}$ directions, respectively; and $\tau_{v x}$ and $\tau_{v y}$ represents vegetation drag for the $\mathrm{x}$ 144 and y directions, respectively.

145 The bed shear stresses can be determined by (Kadlec and Wallace, 2009).

148 The corresponding bed-drag coefficient $\left(C_{b D}\right)$ is defined as:

$$
C_{b D}=\frac{3 \mu}{h \rho \sqrt{U_{x}^{2}+U_{y}^{2}}}+\frac{M^{2} g}{h^{\frac{1}{3}}}=\frac{3}{\operatorname{Re}}+\frac{M^{2} g}{h^{\frac{1}{3}}}
$$

150 in which $\mu$ is the water dynamic viscosity; $M$ is the Manning friction coefficient; and $R e=$ $\rho \mu U / h$ is the depth Reynolds number. The bed drag coefficient consists of two terms. Under laminar and transitional flow $(R e \leq 500)$, the first term dominates, whereas the second turbulent term, characterized by the Manning equation, dominates for larger Reynolds numbers ( $R e \geq 1250)$ (Musner et al., 2014).

155 Vegetation drag is modeled using the following expressions for the drag exerted by the stems, as described by (Werner and Kadlec, 1996).

$$
\begin{aligned}
& \tau_{v x}=\rho C_{v D} a l \frac{U_{x}}{2} \sqrt{U_{x}^{2}+U_{y}^{2}} \\
& \tau_{v y}=\rho C_{v D} a l \frac{U_{y}}{2} \sqrt{U_{x}^{2}+U_{y}^{2}}
\end{aligned}
$$


where $C_{v D}$ is the vegetation-drag coefficient (dimensionless), and $l$ is the stem height

160 (assumed equal to water depth). If the plants are modeled as cylinders, the vegetation density parameter $(a)$ can be defined as:

$$
a=n_{s} d
$$

163 in which $n_{s}$ is the number of vegetation stems per unit area $\left(1 / \mathrm{m}^{2}\right)$, and $d$ is the stem diameter 164 (m). From Eq. 9 a non-dimensional vegetation volume fraction is defined as $V F=a d=n_{s} d^{2}$, which represents the volume fractional of the flow domain occupied by plants (Nepf, 1999; Stoesser et al., 2010).

\subsubsection{Solute transport model}

168 Solute transport of a passive tracer through a wetland was simulated with a depth-averaged 169 solute transport model,

$\frac{\partial(h \mathrm{C})}{\partial t}+\frac{\partial\left(h U_{x} C\right)}{\partial x}+\frac{\partial\left(h U_{y} C\right)}{\partial y}=\frac{\partial}{\partial x}\left(h E_{x x} \frac{\partial C}{\partial x}+h E_{x y} \frac{\partial C}{\partial y}\right)+\frac{\partial}{\partial y}\left(h E_{y x} \frac{\partial C}{\partial x}+h E_{y y} \frac{\partial C}{\partial y}\right)$

171 in which $C$ is the depth-averaged solute concentration. Since we cannot assume that the xaxis is everywhere parallel to the local flow vector, the mixed dispersion coefficients, $E_{i j}$, must be retained. They can be written in terms of their longitudinal $\left(E_{L}\right)$ and transverse $\left(E_{T}\right)$ components (Arega and Sanders, 2004):

$$
E_{x x}=\mathrm{E}_{\mathrm{L}}+\left(\mathrm{E}_{\mathrm{L}}-\mathrm{E}_{\mathrm{T}}\right) \frac{U_{x}^{2}}{U_{x}^{2}+U_{y}^{2}}
$$

$$
E_{x y}=E_{y x}=\mathrm{E}_{\mathrm{L}}+\left(\mathrm{E}_{\mathrm{L}}-\mathrm{E}_{\mathrm{T}}\right) \frac{U_{x} U_{y}}{U_{x}{ }^{2}+U_{y}{ }^{2}}
$$

$$
E_{y y}=\mathrm{E}_{\mathrm{L}}+\left(\mathrm{E}_{\mathrm{L}}-\mathrm{E}_{\mathrm{T}}\right) \frac{U_{y}^{2}}{U_{x}^{2}+U_{y}^{2}}
$$

An equation to determine transverse diffusion for flow through emergent vegetation was proposed by Nepf (1999). Total transverse diffusion is expressed as the combination of both mechanical and turbulent diffusion Eq (14):

$$
\frac{E_{T}}{U_{x} \mathrm{~d}}=\alpha_{h}\left(C_{v D} a d\right)^{\frac{1}{3}}+\frac{\beta^{2}}{2} a d
$$

182 The first term, turbulent diffusion, is based on the assumption that all the energy extracted 183 from the mean flow through stem (cylinder) drag appears as turbulent kinetic energy. The second term accounts for the mechanical diffusion and arises from the dispersal of fluid particles due to obstruction of flow by vegetation stems. Nepf (1999) compared the 
predictions of Eq. (14) with experimental data from laboratory experiments in the range of stem Reynolds number, $R e_{d}=\frac{U d}{v}=400$ to 2000 and field experiments in the range $R e_{d}=300$ to 600 and found a good agreement for scale factors of $\alpha_{h}=0.81, \beta=1$. Turbulent diffusion is not present $\left(\alpha_{h}=0\right)$ for conditions with $\operatorname{Re}_{d}<200$, for which viscous drag dominates and dissipates mean flow energy without generating turbulence.

Longitudinal dispersion $\left(E_{L}\right)$ reflects the effects of stem-scale longitudinal dispersion processes and the dispersion induced by vertical velocity gradients, which, for emergent vegetation, are associated with vertical variation in plant morphology. Lightbody and Nepf (2006) used tracer studies and velocity measurements in a marsh with emergent vegetation and for depth-averaged velocity in the range 0.1 and $0.24 \mathrm{~cm} \mathrm{~s}^{-1}\left(R e_{d}=2-360\right)$ to determine longitudinal dispersion coefficient $E_{L}$. The non-dimensional form of the longitudinal dispersion coefficient is written as a combination of the stem-scale and the depth-scale dispersion process as:

$$
\frac{E_{L}}{U_{x} \mathrm{~d}}=\frac{1}{2}\left(C_{v D}\right)^{\frac{3}{2}}+\frac{U_{x} \mathrm{~h}}{D_{z}} \Gamma
$$

in which $D_{z}=\alpha_{z}\left(C_{v D} a d\right)^{\frac{1}{3}} U d$ is the vertical turbulent diffusion coefficient $\left(\alpha_{z}=0.81\right.$, (Lightbody and Nepf, 2006)), and $\Gamma$ is the non-dimensional velocity shape factor. As noted by Lightbody and Nepf (2006), the first term of equation (15) is typically smaller than the second term, and can be neglected. For the range of stem Reynolds numbers investigated in this study it is reasonable to consider only the first term of equation (14) and only the second term of equation (15).

\subsection{Residence time distribution}

Tracer tests are used to evaluate the hydraulic efficiency of a wetland (Bodin et al., 2012; Holland et al., 2004; Koskiaho, 2003). A non-reactive tracer is introduced at the wetland inlet, and the outlet concentration is measured as a function of time, $C_{\text {out }}(t)$, from which the residence time distribution, $\mathrm{r}(\mathrm{t})$, can be found.

$$
r(t)=\frac{Q_{\text {out }}(t) C_{\text {out }}(t)}{\int_{0}^{\infty} Q_{\text {out }}(t) C_{\text {out }}(t) d t}
$$

with volumetric outflow $Q_{o u t}(t)$. The first moment of the RTD is the mean residence time, $t_{m}$, which is the average time that tracer particles remain in the wetland (Bodin et al., 2012),

$$
t_{m}=\int_{0}^{\infty} \operatorname{tr}(t) d t
$$


215 If the flow passes through the entire volume (i.e. there are no dead-zones), the measured 216 mean residence time equals the nominal residence time, i.e. $t_{m}=t_{n}=V / Q$. The second 217 moment of $r(t)$, i.e. the variance $\left(\sigma^{2}\right)$, is:

$$
\sigma^{2}=\int_{0}^{\infty}\left(t-t_{m}\right)^{2} r(t) d t
$$

219 which describes the range of possible residence times for different individual fluid parcels. A 220 large variance indicates that there is a large variation in the times spent by individual parcels of water within the wetland. This variation can be caused by the presence of different flow paths, e.g. short-circuiting flow paths and recirculation zones, or by a high level of turbulent mixing. For plug flow, for which there is no mixing and a perfectly uniform flow field, the variance is equal to zero.

A wetland can be modeled as a number $(N)$ of continuous stirred tank reactors (CSTRs) in series (Kadlec and Wallace, 2009). In the case of a single tank $(N=1)$, water is uniformly and instantly mixed over the entire wetland, and the wetland behaves as a wellmixed reactor, resulting in an exponential RTD with $\sigma=t_{n}$. In contrast, a model with a large number of tanks (large $\mathrm{N}$ ) produces a system approaching plug flow, with a low degree of overall mixing and small variance $\left(\sigma^{2}\right)$. According to Fogler (1992), the number of tanks in series, $N$, can be determined from the inverse of the dimensionless variance $\left(\sigma_{\theta}=\sigma / t_{n}\right)$ :

$$
N=\left(\sigma_{\theta}\right)^{-2}=\left(\frac{\sigma}{t_{n}}\right)^{-2}
$$

233 The dimensionless variance or the number of CSTRs can be used to compute the dispersion 234 efficiency of the wetland (Persson et al., 1999):

$$
e_{d}=1-\left(\sigma_{\theta}\right)^{2}=1-\left(\frac{1}{N}\right)
$$

236 In the ideal limit of plug flow, $\sigma^{2}=0$, resulting in $e_{d}=1$. This represents the best treatment conditions with the lowest exit concentration.

238 Another metric of wetland efficiency is the volumetric efficiency, $e_{v}$, (Persson et al., 1999), 239 representing the effective volume of a wetland system. It is determined as the ratio of the 240 mean residence time $\left(t_{m}\right)$ and the nominal residence time $\left(t_{n}\right)$.

$$
e_{v}=\left(\frac{t_{m}}{t_{n}}\right)=\left(\frac{\mathrm{A}_{\text {effective }}}{A_{\text {total }}}\right)
$$


242 Assuming a uniform depth, this also indicates the ratio of effective flow area $\left(A_{\text {effective }}\right)$ to total 243 pond surface area $\left(A_{\text {total }}\right)$. Low values of $e_{V}(<1)$ indicate the presence of dead zones $\left(A_{\text {effective }}\right.$

$\left.244<A_{\text {total }}\right)$. Persson et al. (1999) also defined a hydraulic efficiency index, $\lambda_{h}$, incorporating 245 both the effects of retention time and dispersion.

$$
\lambda_{h}=e_{v}\left(1-\frac{1}{N}\right)
$$

247 A high value of this index indicates that few dead zones are present $\left(e_{V} \approx 1\right)$ and low levels of 248 dispersion are present, both of which lead to better wetland performance.

\section{3. Methodology}

250 This numerical model study investigated the effects of wetland shape, inlet-outlet configuration, and vegetation density on the hydrodynamics and mass removal capabilities of FWS wetlands. The size of all basins (Fig. 1) was set at 1 hectare, and a range of vegetation density was assumed, from non-vegetated to 1000 stems $/ \mathrm{m}^{2}$ (Kadlec and Wallace, 2009;

254 Serra et al., 2004). The boundary conditions were defined for Eqs. (1)- (3), by the inflow at 255 the inlet, $7.7 \mathrm{~L} / \mathrm{s}$, and the water depth at the outlet, $0.5 \mathrm{~m}$, producing a nominal hydraulic retention time of $t_{n}=7.5$ days. The vegetation drag was described by equations (7) and (8) by assuming that the stem diameter was uniform and equal to $d=5 \mathrm{~mm}$, which is a reasonable assumption for vegetation found in a FWS constructed wetland. In real constructed wetlands aquatic vegetation may be quite dense ( $V F$ up to 0.050 ), with diameters of 4-15 mm (Serra et al., 2004). The values of VF in the model are 0 to 0.025 .

(a)

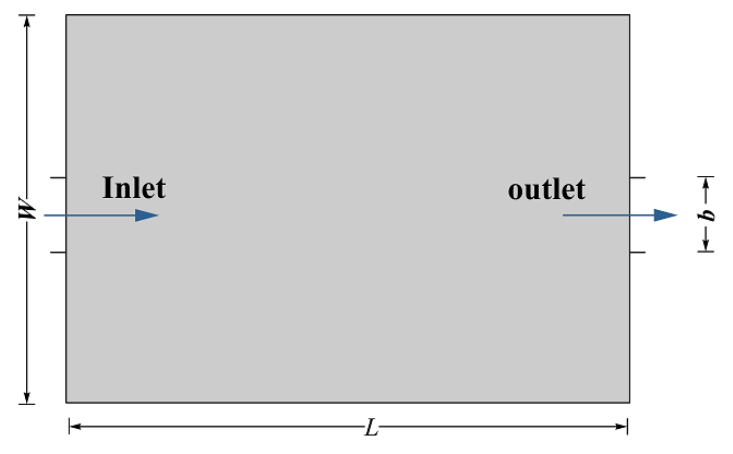

(b)

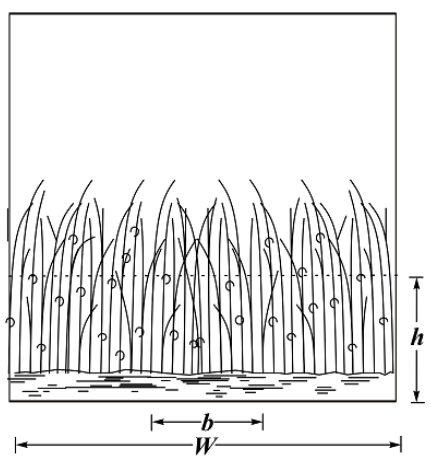

Fig 1. Illustration of a rectangular wetland with centrally aligned inlet and outlet and uniform vegetation coverage: (a) plan view, (b) side view. 


\subsection{Model calibration and validation}

265 Four parameters; vegetation density, transverse diffusivity, $E_{T}$, longitudinal dispersion

266 coefficient, $E_{L}$, and Manning coefficient $(M)$; were used for model calibration. A sensitivity

267 analysis was carried out by initially considering parameters that represented average values of

$268 E_{T}$ and $E_{L}$ determined from Eq. (14) using the scale factors $\alpha_{h}=0.1, \beta=1$, as derived from

269 the experimental studies (Nepf, 1999) and $\alpha_{v}=0.1$ (Eq. 15) (Lightbody and Nepf, 2006;

270 Tanino and Nepf, 2008). The model output was used to calculate the volumetric efficiency,

$271 e_{v}$, which was compared to the following empirical relation derived by Thackston et al.

272 (1987), based on survey data from a wide variety of vegetated types, sizes, and shapes of

273 large, shallow wetlands (Fig. 2).

$$
e_{v}=0.85\left(1-\exp \left(-0.59\left(\frac{\mathrm{L}}{\mathrm{W}}\right)\right)\right)
$$

275 Applying a best-fit calibration for a vegetation density of $50 \mathrm{stems} / \mathrm{m}^{2}$, the Manning

276 coefficient that produced the best match between the model and the design curve was found

277 to be $M=0.02 \mathrm{~m}^{-1 / 3} \mathrm{~s}$. The vegetation density of $50 \mathrm{stems} / \mathrm{m}^{2}$ was chosen because the

278 contribution of bed friction is higher at low density. In the calibration, $60 \%$ of the simulations

279 were used (with $L: W$ aspect ratios of 1:1, 2:1,5:1, 6:1, 8:1, 10:1) whereas the remaining $40 \%$

280 was applied for model validation. As shown in Figure 2, the numerical model results fit well

281 with the field data presented by Thackston et al. (1987). The relative errors of rectangular and

282 ellipse wetlands to the field data were $8 \%$ and $11 \%$, respectively (Fig. 2). The numerical

283 modeling studies by Jenkins and Greenway (2005) and Minsu et al. (2009) have also

284 calibrated sets of hypothetical wetlands according to the design curve proposed by Thackston

285 et al. (1987), and both found a good fit between $L: W$ and the simulated detention time.

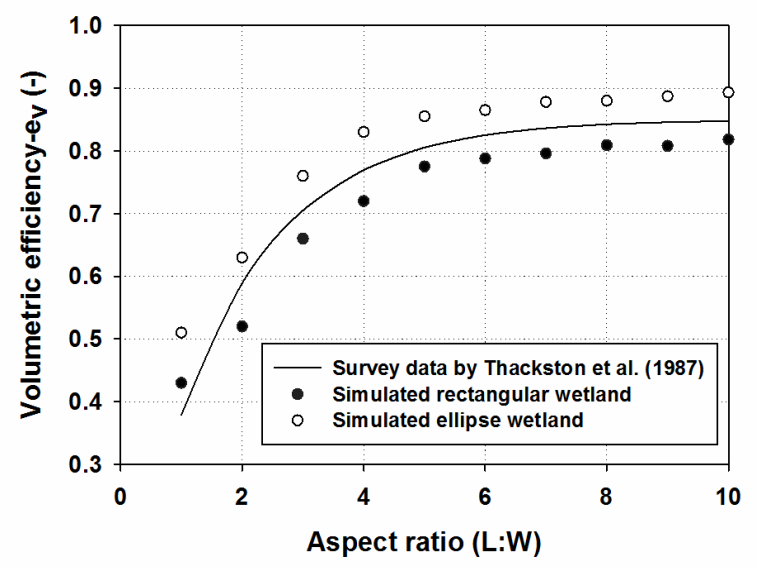




\section{3.2. Model application}

290 Eight hypothetical wetlands, including four rectangular (R) and four elliptical wetlands (E) of 291 aspect ratios (1:1, 2:1, 3:1, 4:1), were modeled (Table. 1). Elliptical wetlands were considered 292 because this geometry is likely to increase the detention time by reducing the area of dead

293 zones at the corners of the wetland, which should reduce the variance and increase the 294 volumetric efficiency $\left(e_{v}\right)$ of the RTD. The flow was modeled for a constant discharge rate 295 through an inlet of $10 \mathrm{~m}$ width and an outlet with $10 \mathrm{~m}$ width. Both the inlet and the outlet 296 were centrally located (Fig. 1). The effect of inlet-outlet configuration was also examined. In 297 these cases the shape, area and discharge rate were kept constant, and four different inlet298 outlet configurations for a rectangular wetland of aspect ratio 4:1, R4, were considered, 299 including a single inlet in the right corner and single central outlet (i.e. case R4-a); a single 300 right corner inlet and the outlet located in left corner (i.e. Case R4-b); a double-inlet wetland 301 (i.e. R4-i2) and a triple-inlet (i.e. R4-i3). The inlet width of $10 \mathrm{~m}$ was used for all the cases.

302 The aspect ratio 4:1 complies with common design guidelines which recommend aspect 303 ratios higher than 3:1 (EPA, 2000; Kadlec and Wallace, 2009).

304 For the solute transport equation, the boundary conditions were given by a instantaneous 305 tracer injection at the inlet, $C=1 \mathrm{~kg} / \mathrm{m}^{3}$, an open boundary condition at the outlet, and a no306 flux condition on the remaining part of the flow boundary. The equations were solved via a

307 finite element method (FEM) using COMSOL Multiphysics ${ }^{\circledR}$ with quadratic shape functions.

308 The computational grid was made of approximately 150000 triangular elements, with higher

309 spatial resolution near the inlet and the outlet, and a maximum element size of $2 \mathrm{~m}$.

\section{4. Results and discussion}

311 The RTDs (Fig.3) and velocity fields (Fig. 4 and 6) were generated for all configurations. 


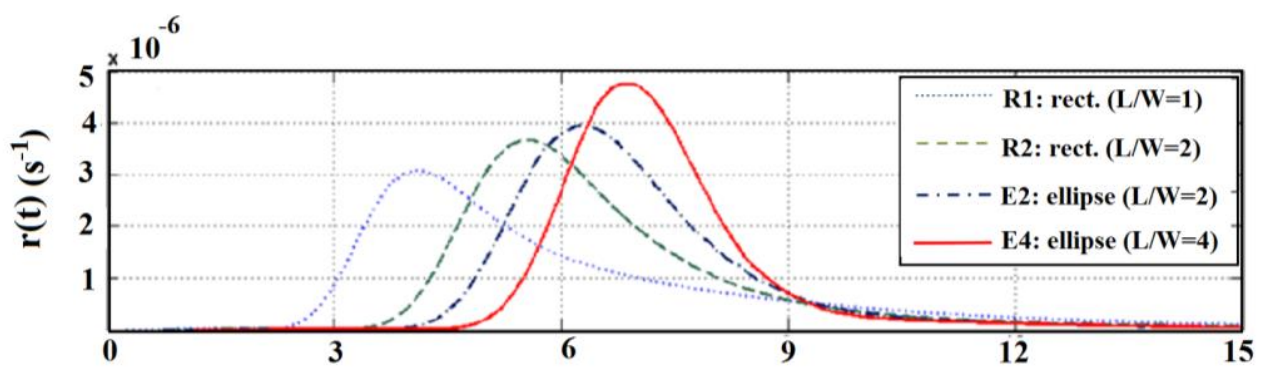

Time (Day)

Fig 3. Simulated RTDs of wetlands with different aspect ratio and different shape.

314 Table. 1 shows the several parameters derived from the RTDs for each of the simulated

315 wetlands for vegetation coverage $100 \mathrm{stems} / \mathrm{m}^{2}$ and inlet width to wetland width ratio of 0.1

$316(b / \mathrm{W}=0.1)$. The mean residence time was in the range $t_{m}=1.6$ to 6.9 days, which was less

317 than the nominal residence time of 7.5 days. The number of tanks in series, $N$, for FWS

318 wetlands are generally in the range $0.3<N<10.7$ with a mean of $N=4.1 \pm 0.4$ (Holland et

319 al., 2004; Kadlec and Wallace, 2009). Therefore, the range of NTIS values obtained in this

320 study, $1.2<N<11.1$, was representative of FWS wetlands and not unusual for free water

321 surface wetlands.

Table 1: Summary of configurations and simulated results for a wetland with nominal residence time $t_{n}=$ $323 \quad 7.5$ days and a vegetation coverage of $100 \mathrm{stems} / \mathrm{m}^{2}$.

\begin{tabular}{|c|c|c|c|c|c|c|c|c|}
\hline Case & $\begin{array}{l}\text { Dimension } \\
(\mathrm{m} \times \mathrm{m})\end{array}$ & $L / W$ & $t_{m}$ (day) & $\sigma^{2}$ & $\boldsymbol{e}_{v}$ & $e_{d}$ & $\lambda_{h}$ & Config. \\
\hline R1 & $(100 \times 100)$ & 1 & 5.3 & 0.50 & 0.71 & 0.50 & 0.36 & $\rightarrow$ \\
\hline R2 & $(141 \times 71)$ & 2 & 6.1 & 0.24 & 0.82 & 0.76 & 0.62 & $\longrightarrow \rightarrow$ \\
\hline R3 & $(173 \times 58)$ & 3 & 6.3 & 0.18 & 0.84 & 0.82 & 0.69 & 7 \\
\hline $\mathrm{R} 4$ & $(200 \times 50)$ & 4 & 6.8 & 0.16 & 0.91 & 0.84 & 0.77 & $\rightleftarrows \quad \exists$ \\
\hline E1 & $(113 \times 113)$ & 1 & 6.1 & 0.34 & 0.81 & 0.66 & 0.53 & \\
\hline E2 & $(160 \times 80)$ & 2 & 6.5 & 0.25 & 0.86 & 0.75 & 0.65 & $\leftarrow$ \\
\hline E3 & $(195 \times 65)$ & 3 & 6.6 & 0.16 & 0.88 & 0.84 & 0.74 & \\
\hline E4 & $(224 \times 56)$ & 4 & 7.1 & 0.09 & 0.95 & 0.91 & 0.86 & $\leftrightarrow$ \\
\hline R4-a & & & 5.3 & 0.29 & 0.82 & 0.71 & 0.58 & 7 \\
\hline R4-b & $(200 \times 50)$ & 4 & 6.6 & 0.12 & 0.94 & 0.88 & 0.83 & $\leftarrow$ \\
\hline R4-2i & & & 6.9 & 0.08 & 0.93 & 0.92 & 0.85 & $\rightleftarrows$ \\
\hline R4-3i & & & 7.1 & 0.06 & 0.94 & 0.94 & 0.88 & - $\#$ \\
\hline
\end{tabular}




\subsection{Wetland Aspect Ratio and Shape}

Persson (1999) categorized wetlands into three categories. A wetland with good performance must have hydraulic efficiency $\lambda_{h} \geq 0.75$, whereas hydraulic efficiencies of $0.50 \leq \lambda_{h} \leq 0.75$ correspond to satisfactory performance, and $\lambda_{h} \leq 0.5$ correspond to low performance. First, for both elliptical and rectangular wetland shapes, increasing the aspect ratio $(\mathrm{L} / \mathrm{W})$ increased both the volumetric efficiency, $e_{v}$, and dispersion index, $e_{d}$, indicating improved treatment performance (Table 1). This was consistent with previous studies for rectangular wetlands (Jenkins and Greenway, 2005; Persson et al., 1999). For example, for rectangular wetlands with $100 \mathrm{stems} / \mathrm{m}^{2} e_{v}$ and $e_{d}$ increase by $28 \%$ and $68 \%$, respectively, with an increase in aspect ratio from $L / W=1$ to $L / W=4$ (Table 1). Likewise, for elliptical wetlands with 100 stems $/ \mathrm{m}^{2} e_{v}$ and $e_{d}$ increased by $17 \%$ and $38 \%$, respectively, between $L / W$ $=1$ to 4 (Table 1$)$.

Second, for the same area, depth, discharge rate, and aspect ratio elliptical wetlands consistently had better performance than rectangular ones, i.e. produced higher values of $e_{v}$, $e_{d}$, and $\lambda_{h}$, (Table 1). The better performance arose from the difference in flow pattern, as shown in Figure 4. Larger dead zones (denoted by black color in Figure 4) occurred in the corners of rectangular wetlands than in elliptical ones. The presence of dead zones (regions of zero velocity) meant that some fraction of the wetland was excluded from the main flow path, and consequently the effective wetland area $\left(A_{\text {effective }}\right)$ was reduced, reducing $e_{v}$ from 1 . Shifting from a rectangular to an elliptical shape, the dead zones were replaced by regions of moving fluid, increasing the effective wetland area, which then increased $e_{v}$. The difference was largest for the wetlands with the smallest aspect ratio $(L / W=1)$, for which $e_{v}$ increased from 0.71 to 0.81 between a rectangular and elliptical shape. Further, at the inlet the elliptical shape provided a gradual expansion in width, which produced a more uniform cross-sectional velocity profile. This can be seen in the more uniform color of the velocity maps in Figure 4. The range of color (black to red) also provided a general picture of the degree of spatial variation in the velocity field. A smaller spatial variation in the velocity field is associated with smaller wetland scale dispersion. Consistent with this, the elliptical wetlands produce higher values of $e_{d}$ (Table 1). Recall from eq (21) that $e_{d}=1$ for plug-flow, for which there is no dispersion. The trends were consistent across all stem densities. Specifically, for the same aspect ratio, elliptical wetlands consistently produced higher values of both $e_{v}$ and $e_{d}$ (Figure $5)$. 

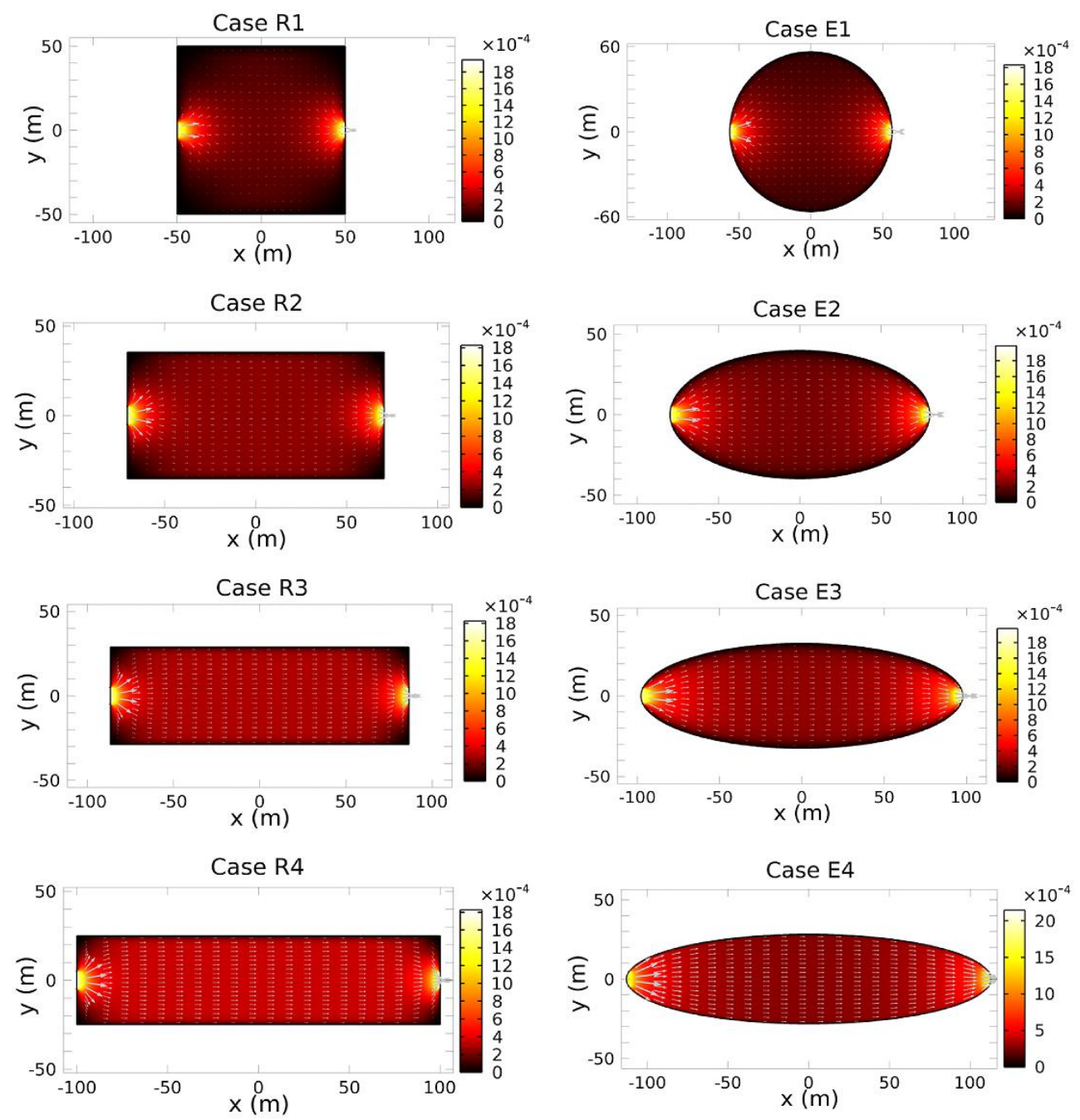

357 Fig 4: Simulated velocity fields for different wetland shapes of 1 ha area and a centrally aligned inletoutlet of $10 \mathrm{~m}$ width and $100 \mathrm{stems} / \mathrm{m}^{2}$ vegetation density. 

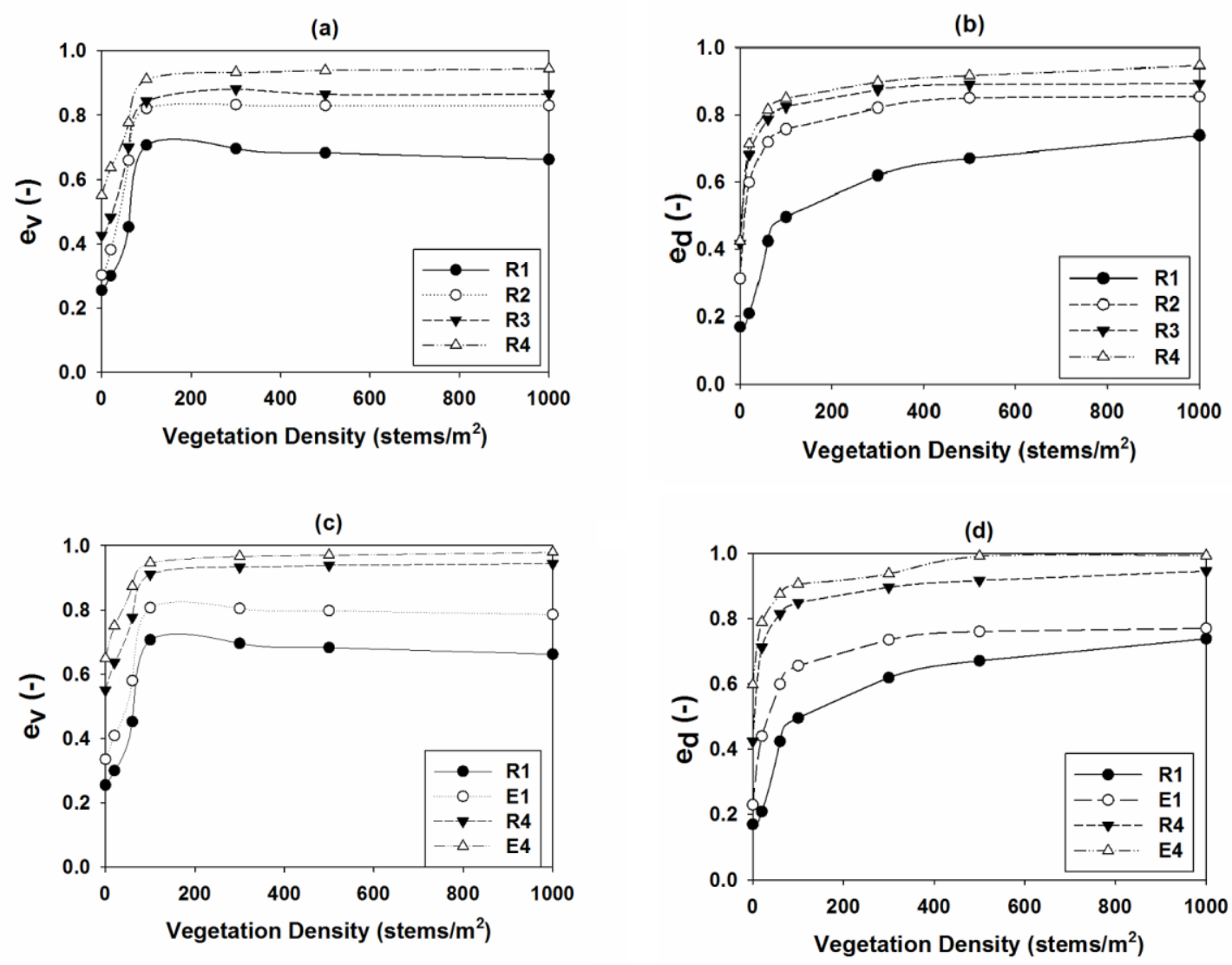

360 Fig 5. The effect of (a), (c) aspect ratio and (b), (d) wetland shape on volumetric and dispersion efficiency 361 of wetlands with different vegetation density.

The simulation results revealed an interesting threshold behavior with regard to stem

363 density (Figure 5). A change in wetland vegetation density between zero and $150 \mathrm{stems} / \mathrm{m}^{2}$

364 was associated with a significant increase in volumetric efficiency, $e_{v}$ (Figure 5a and 5c), but

365 further increasing stem density provided little additional improvement. A similar threshold

366 was observed for dispersion efficiency, $e_{d}$, but occurred at a slightly higher stem density, 300

367 stems $/ \mathrm{m}^{2}$ (Figure $5 \mathrm{~b}$ and $5 \mathrm{~d}$ ). The same threshold (300 stems $/ \mathrm{m}^{2}$ ) was also observed in the

368 overall hydraulic efficiency parameter, $\lambda_{\mathrm{h}}$ (Figure 6). The presence of this threshold has

369 important implications for predictive modeling, because it suggests that knowledge of the

370 exact stem density may not be necessary. As long as the stem density is above $300 \mathrm{stems} / \mathrm{m}^{2}$,

371 which is typical of treatment wetlands (Serra et al., 2004), predictions will not be sensitive to

372 the exact value of stem density selected, which simplifies the parameterization of models. 

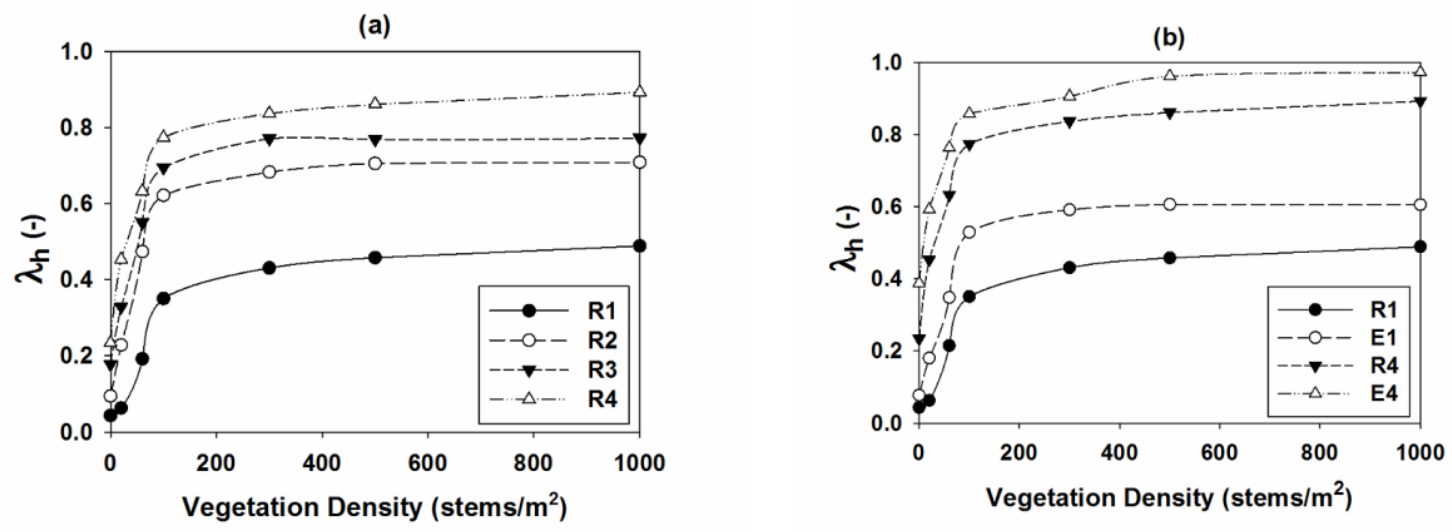

Fig 6. The effect of (a) aspect ratio and (b) shape variation on hydraulic efficiency of wetlands with different vegetation density.

\subsection{Inlet-outlet configuration and size}

Modification of the inlet-outlet position and size affected the flow distribution within the wetland systems (Figure 7). First, consider the cases for which the inlet width $(b)$ to wetland width $(W)$ ratio was $b / \mathrm{W}=0.1$. An asymmetric alignment of inlet and outlet, case $\mathrm{R} 4-\mathrm{a}$ (Fig. 7a), produced a larger dead-zone away from the inlet-outlet couple (lower left corner in Figure 7a), compared to a symmetric inlet-outlet, R4 (Fig. 4). The larger dead-zone reduced the effective volume of wetland, which resulted in a lower value of volumetric efficiency, $e_{v}$. Specifically, $e_{v}$ dropped from 0.91 for the symmetric case R4 to 0.82 for the asymmetric case R4-a (Fig. 8.a, 8.b). On the other hand, moving the inlet and outlet to opposite corners, case R4-b, improved the volumetric efficiency, relative to the symmetric base case R4. In fact, the opposite corner configuration produced the highest volumetric efficiency of $e_{v}=0.94$ (Fig 7.b, Fig. 8.a). Similarly, the opposite corner configuration (R4-b) also produced the highest value of $e_{d}=0.88$, compared to 0.84 for the symmetric base case R 4 and $e_{d}=0.71$ for the asymmetric case R4-a, indicating that the opposite corner inlet-outlet configuration produced the least dispersion (Fig. 8.a, 8.b). Consistent with this, the opposite corner configuration also produced the highest hydraulic efficiency, with $\lambda_{h}=0.83$, compared to 0.77 for the symmetric base case (R4) and just 0.58 for the asymmetric case R4-a. Finally, for each inletoutlet configuration the ratio between the inlet width (b) and the wetland width $(W)$ was varied between 0.1 to 1 (Fig. 8). As $b / \mathrm{W}$ increased, cases $\mathrm{R} 4$ and R4-a experienced a consistent increase in $e_{v}$ and $e_{d}$ from 0.82 and 0.98 and 0.71 and 0.97 , respectively (Fig. 8). 
However, for the opposite corner case R4-b the variation of the inlet width had little impact on the efficiency parameters (Fig. 8).

The use of multiple inlets improved all of the efficiency metrics $\left(e_{v}, e_{d} \lambda_{h}\right)$. The velocity field showed that the area of dead zone (black areas) was diminished in the both the double-inlet (case R4-2i, Fig 7.c) and the triple inlet (case R4-3i, Fig. 7d) systems, compared to the symmetric, single-inlet reference wetland (case R4, Fig. 4). In addition, multiple inlets (Figure 7c, 7d) produced a more uniform velocity field (more uniform color in Figure 7), compared to the single inlet case R4(Fig. 4).

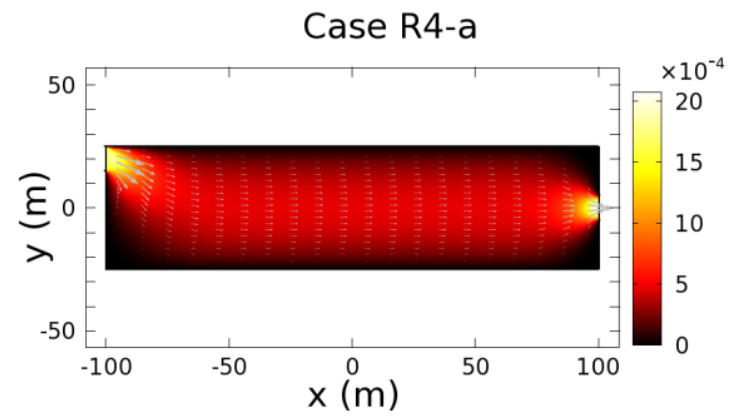

Case R4-2i

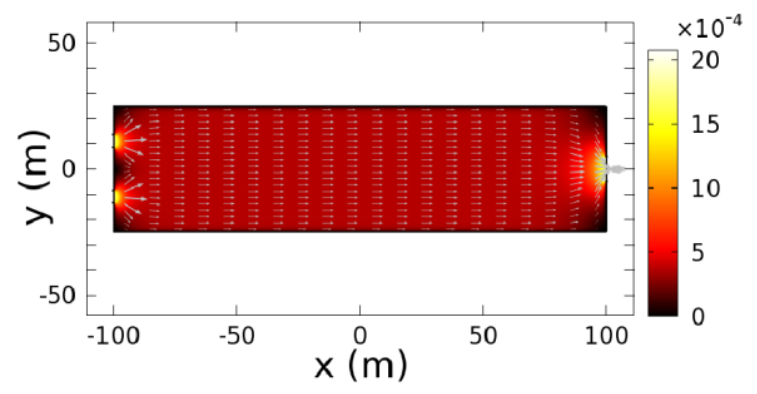

Case R4-b

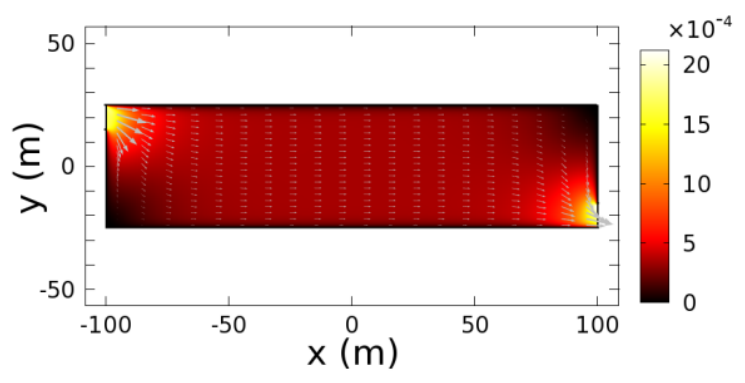

Case R4-3i

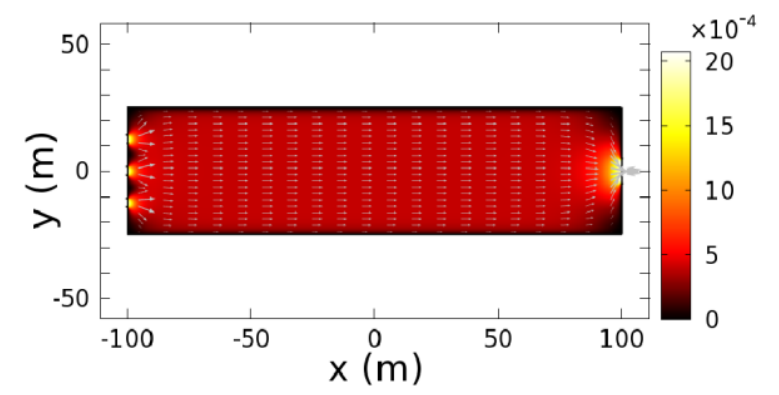

404

405

406

407

408

409

410

411

412

413

414

415

416

417

Fig 7: Simulated velocity fields for different inlet and outlet configurations for a rectangular wetland with $100 \mathrm{stems} / \mathrm{m}^{2}$ vegetation density and an outlet of $10 \mathrm{~m}$ width: (a) Case R4-a, left inlet of $10 \mathrm{~m}$ width and central outlet (b/W=0.1); (b) Case $R 4-b$, a left inlet of $10 \mathrm{~m}$ width and right outlet ; (c) Case R4-2i, double inlet of $5 \mathrm{~m}$ width; (d) Case R4-3i, triple inlet of $3.33 \mathrm{~m}$ width. Black regions represent dead zones, i.e. regions of zero velocity.

The presence of multiple inlets significantly changed the values of retention time and RTD variance (table 1). For $b / \mathrm{W}=0.1$, the velocity field became more uniform as the number of inlets increased (see Figure 7), which resulted in lower RTD variance (smaller $\sigma \theta$ ), and thus high values of the dispersion parameter $e_{d}$. Specifically, $e_{d}$, was 0.84 for a single-inlet (Case R4), 0.92 for a double-inlet (Case R4-2i) and 0.94 for a triple-inlet (Case R4-3i) (Fig. 8.d). The use of multiple inlets also decreased dead-zone area, which increased the values of volumetric efficiency, $e_{v}$, from 0.91 for $\mathrm{R} 4$ to 0.93 for R4-2i and changed to 0.94 for R4-3i (Fig. 8.c). 

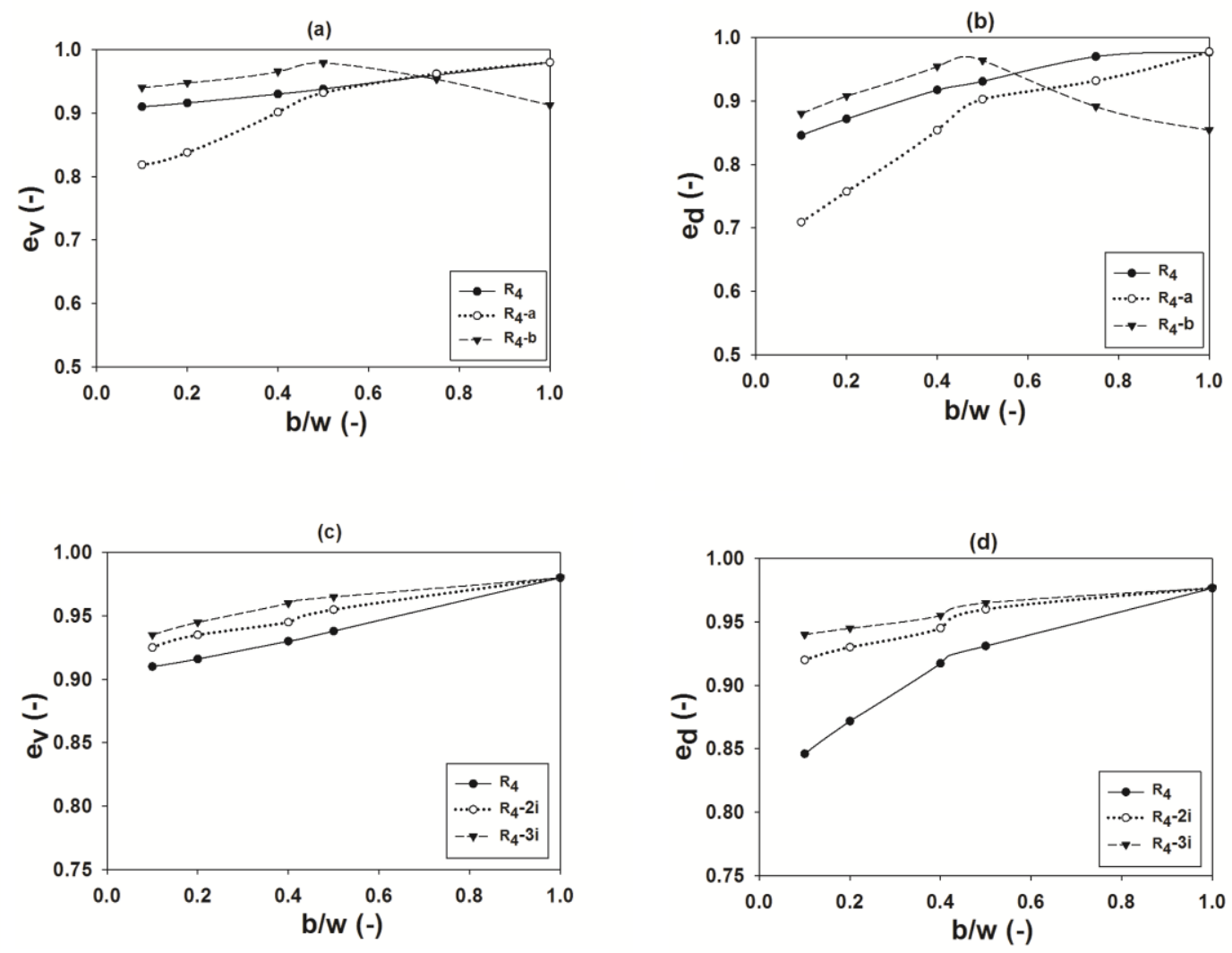

Fig 8. Effect of (a), (c) inlet-outlet position and (b), (d) number of inlets on volumetric and dispersion 420 efficiency of rectangular wetlands of aspect ratio $4: 1$ with $100 \mathrm{stems} / \mathrm{m}^{2}$ vegetation coverage and different 421 inlet width.

422 The use of a double inlet (R4-2i) also improved the hydraulic efficiency $\left(\lambda_{h}\right)$ by $8 \%$, relative 423 to the base case with a single inlet R4 (Figure 9). However, increasing to a third inlet (case 424 R4-3i), did not produce further improvement (Figure 9). The primary advantage of widening 425 the inlet or using multiple inlets was to create a more uniform velocity field with smaller 426 dead-zone area. Therefore, as the inlet width increased (increasing $b / \mathrm{W}$ ), the added benefit of 427 multiple inlets diminished, and the efficiency parameters converge to a single value for $b / \mathrm{W}$ $428=1$ (Figure 9).

(a)

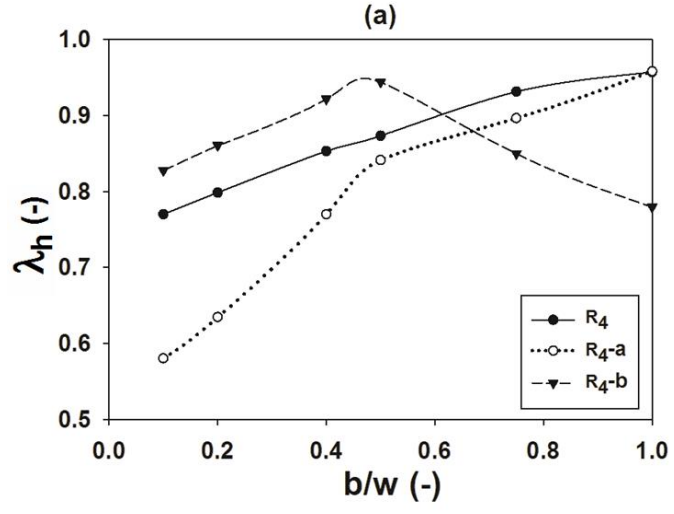

(b)

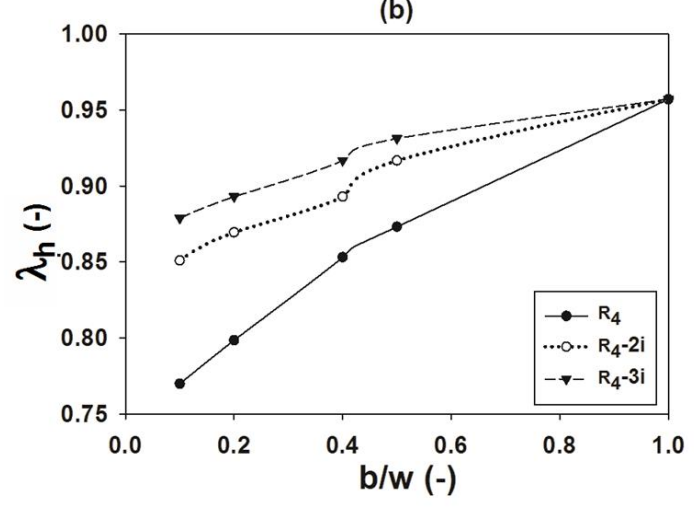




\section{Conclusion}

433 This study showed that performance of a wetland can be improved by appropriately

434 designing wetland shape, aspect ratio and inlet-outlet configuration. Ellipse-shaped wetlands yielded higher detention time (higher $e_{v}$ ) and less dispersion (higher $e_{d}$ ) compared to rectangular wetlands with similar characteristics. Unlike a rectangular wetland, in which prominent dead-zones formed in each corner of the wetland, an elliptical wetland produced a more uniform velocity distribution with fewer (or no) dead zones, increasing $e_{v}$, reducing RTD variance and thus increase the dispersion efficiency $e_{d}$. The reduction in dead-zone size and the more uniform velocity field of the elliptical wetland implies performance greater potential for pollutant removal.

Higher vegetation density was associated with lower variances in the RTD and larger NTIS.

443 However, above a threshold stem density of about $300 \mathrm{stems} / \mathrm{m}^{2}$, the dispersion efficiency

$444\left(e_{d}\right)$, and volumetric efficiency $\left(e_{v}\right)$ remained almost constant, i.e. increasing vegetation density further did not significantly improve these efficiency metrics. From a design and management point of view, determining this threshold vegetation density can be useful for a cost-effective wetland design and operation.

448 Both parameters related to volumetric retention time and dispersion rate, $e_{v}$ and $e_{d}$, can also

449 be improved by adjusting the inlet-outlet configuration. The minimum dead zone area

450 (greatest effective area) and the lowest dispersion were achieved with the opposite corner-tocorner inlet-outlet configuration, which produced the maximum values of $e_{v}$ and $e_{d}$, respectively (Figure 8). On the other hand, an asymmetric inlet-outlet layout with the inlet at a corner and a centrally aligned outlet produced the lowest hydraulic efficiency. This is due to the fact that the flow can pass from the inlet to the outlet without entering the opposite side of the wetland volume, such that a large fraction of the wetland volume is excluded from the circulation. Finally, using multiple inlets and increasing the inlet to wetland width ratio $(b / \mathrm{W})$ both improved the hydraulic efficiency by reducing dead zone area and producing a more uniform velocity field within the wetland.

Acknowledgments This work was supported by the Research Executive Agency, through

460 the Seventh Framework Programme of the European Union, Support for Training and Career

461 Development of Researchers (Marie Curie-FP7-PEOPLE-2012-ITN), which funded Initial 


\section{References}

465

466

467

468

469

470

471

472

473

474

475

476

477

478

479

480

481

482

483

484

485

486

487

488

489

490

491

492

493

494

495

496

497

498

499

500

501

Arega, F., Sanders, B.F., 2004. Dispersion model for tidal wetlands. J. Hydraul. Eng. 130, 739-754. doi:10.1061/(ASCE)0733-9429(2004)130:8(739)

Batty, L.C., Younger, P.L., 2002. Critical role of macrophytes in achieving low iron concentrations in mine water treatment wetlands. Environ. Sci. Technol. 36, 3997-4002.

Bodin, H., Mietto, A., Ehde, P.M., Persson, J., Weisner, S.E.B., 2012. Tracer behaviour and analysis of hydraulics in experimental free water surface wetlands. Ecol. Eng. 49, 201211. doi:10.1016/j.ecoleng.2012.07.009

Cameron, K., Madramootoo, C., Crolla, A., Kinsley, C., 2003. Pollutant removal from municipal sewage lagoon effluents with a free-surface wetland. Water Res. 37, 28032812. doi:10.1016/S0043-1354(03)00135-0

Carleton, J.N., Grizzard, T.J., Godrej, a. N., Post, H.E., 2001. Factors affecting the performance of stormwater treatment wetlands. Water Res. 35, 1552-1562. doi:10.1016/S0043-1354(00)00416-4

EPA, 2000. Manual Constructed Wetlands Treatment of Municipal Wastewaters Manual Constructed Wetlands Treatment of Municipal Wastewaters.

Fogler, H.S., 1992. Elements of chemical reaction engineering. Prentice-Hall, Englewood cliffs.

Gill, L.W., Ring, P., Higgins, N.M.P., Johnston, P.M., 2014. Accumulation of heavy metals in a constructed wetland treating road runoff. Ecol. Eng. 70, 133-139. doi:10.1016/j.ecoleng.2014.03.056

Holland, J.F., Martin, J.F., Granata, T., Bouchard, V., Quigley, M., Brown, L., 2004. Effects of wetland depth and flow rate on residence time distribution characteristics. Ecol. Eng. 23, 189-203. doi:10.1016/j.ecoleng.2004.09.003

Hsueh, M.-L., Yang, L., Hsieh, L.-Y., Lin, H.-J., 2014. Nitrogen removal along the treatment cells of a free-water surface constructed wetland in subtropical Taiwan. Ecol. Eng. 73, 579-587. doi:10.1016/j.ecoleng.2014.09.100

Jenkins, G. a., Greenway, M., 2005. The hydraulic efficiency of fringing versus banded vegetation in constructed wetlands. Ecol. Eng. 25, 61-72. doi:10.1016/j.ecoleng.2005.03.001

Kadlec, R., Wallace, S., 2009. Treatment Wetlands, Second edition. CRC Press, Boca raton, Florida.

Kipasika, H.J., Buza, J., Lyimo, B., Miller, W.A., Njau, K.N., 2014. Efficiency of a constructed wetland in removing microbial contaminants from pre-treated municipal wastewater. Phys. Chem. Earth, Parts A/B/C 72-75, 68-72. doi:10.1016/j.pce.2014.09.003

Koskiaho, J., 2003. Flow velocity retardation and sediment retention in two constructed wetland-ponds. Ecol. Eng. 19, 325-337. 
Kotti, I.P., Gikas, G.D., Tsihrintzis, V. a., 2010. Effect of operational and design parameters on removal efficiency of pilot-scale FWS constructed wetlands and comparison with HSF systems. Ecol. Eng. 36, 862-875. doi:10.1016/j.ecoleng.2010.03.002

Lightbody, A.F., Nepf, H.M., 2006. Prediction of velocity profiles and longitudinal dispersion in salt marsh vegetation. Limnol. Oceanogr. 51, 218-228. doi:10.4319/1o.2006.51.1.0218

Mangangka, I.R., Liu, A., Egodawatta, P., Goonetilleke, A., 2015. Sectional analysis of stormwater treatment performance of a constructed wetland. Ecol. Eng. 77, 172-179. doi:http://dx.doi.org/10.1016/j.ecoleng.2015.01.028

Marion, A., Nikora, V., Puijalon, S., Bouma, T., Koll, K., Ballio, F., Tait, S., Zaramella, M., Sukhodolov, A., O’Hare, M., Wharton, G., Aberle, J., Tregnaghi, M., Davies, P., Nepf, H., Parker, G., Statzner, B., 2014. Aquatic interfaces: a hydrodynamic and ecological perspective. J. Hydraul. Res. 52, 744-758. doi:10.1080/00221686.2014.968887

Maucieri, C., Salvato, M., Tamiazzo, J., Borin, M., 2014. Biomass production and soil organic carbon accumulation in a free water surface constructed wetland treating agricultural wastewater in North Eastern Italy. Ecol. Eng. 70, 422-428. doi:10.1016/j.ecoleng.2014.06.020

Musner, T., Bottacin-Busolin, A., Zaramella, M., Marion, A., 2014. A contaminant transport model for wetlands accounting for distinct residence time bimodality. J. Hydrol. 515, 237-246. doi:10.1016/j.jhydrol.2014.04.043

Nepf, H.M., 1999. Drag, turbulence, and diffusion in flow through emergent vegetation. Water Resour. Res. 35, 479-489. doi:10.1029/1998WR900069

Persson, J., Somes, N., Wong, T., 1999. Hydraulics efficiency of constructed wetlands and ponds. Water Sci. Technol. 40, 291-300. doi:10.1016/S0273-1223(99)00448-5

Reed, S.C., Crites, R.W., Middlebrooks, E.J., 1995. Natural Systems for Waste Management and Treatment. McGraw-Hill Professional.

Sabokrouhiyeh, N., Bottacin-Busolin, A., Nepf, H., Marion, A., 2016. Effects of vegetation density and wetland aspect ratio variation on hydraulic efficiency of wetlands, GeoPlanet: Earth and Planetary Sciences. doi:10.1007/978-3-319-27750-9_9

Serra, T., Fernando, H.J.S., Rodríguez, R. V, 2004. Effects of emergent vegetation on lateral diffusion in wetlands. Water Res. 38, 139-47. doi:10.1016/j.watres.2003.09.009

Somes, N.L.G., Bishop, W.A., Wong, T.H.F., 1999. Numerical simulation of wetland hydrodynamics. Environ. Int. 25, 773-779. doi:10.1016/S0160-4120(99)00058-6

Stoesser, T., Asce, M., Kim, S.J., Diplas, P., 2010. Turbulent Flow through Idealized Emergent Vegetation. J. Hydraul. Eng. 136, 1003-1017.

Su, T.-M., Yang, S.-C., Shih, S.-S., Lee, H.-Y., 2009. Optimal design for hydraulic efficiency performance of free-water-surface constructed wetlands. Ecol. Eng. 35, 1200-1207. doi:10.1016/j.ecoleng.2009.03.024

Suliman, F., Futsaether, C., Oxaal, U., Haugen, L.E., Jenssen, P., 2006. Effect of the inletoutlet positions on the hydraulic performance of horizontal subsurface-flow wetlands constructed with heterogeneous porous media. J. Contam. Hydrol. 87, 22-36. doi:10.1016/j.jconhyd.2006.04.009 
Tanino, Y., Nepf, H.M., 2008. Laboratory Investigation of Mean Drag in a Random Array of Rigid, Emergent Cylinders. J. Hydraul. Eng. 134, 34-41.

Tao, W., Hall, K.J., Duff, S.J.B., 2006. Performance evaluation and effects of hydraulic retention time and mass loading rate on treatment of woodwaste leachate in surface-flow constructed wetlands. Ecol. Eng. 26, 252-265. doi:10.1016/j.ecoleng.2005.10.006

Thackston, E.L., Shields, F.D., Schroeder, P.R., 1987. Residence Time Distributions of Shallow Basins. J. Environ. Eng. 113, 1319-1332. doi:10.1061/(ASCE)07339372(1987)113:6(1319)

553

Toet, S., Logtestijn, R.S.P., Kampf, R., Schreijer, M., Verhoeven, J.T.A., 2005. The effect of hydraulic retention time on the removal of pollutants from sewage treatment plant effluent in a surface-flow wetland system. Wetlands 25, 375-391. doi:10.1672/13

Vymazal, J., 2014. Constructed wetlands for treatment of industrial wastewaters: A review. Ecol. Eng. 73, 724-751. doi:10.1016/j.ecoleng.2014.09.034

Vymazal, J., 2013. Emergent plants used in free water surface constructed wetlands: A review. Ecol. Eng. 61, 582-592. doi:10.1016/j.ecoleng.2013.06.023

Vymazal, J., Březinová, T., 2015. The use of constructed wetlands for removal of pesticides from agricultural runoff and drainage: A review. Environ. Int. 75, 11-20.

561 doi:10.1016/j.envint.2014.10.026

Werner, T.M., Kadlec, R.H., 1996. Application of residence time distributions to stormwater treatment systems. Ecol. Eng. 7, 213-234. doi:10.1016/0925-8574(96)00013-4

Wu, S., Wallace, S., Brix, H., Kuschk, P., Kirui, W.K., Masi, F., Dong, R., 2015. Treatment of industrial effluents in constructed wetlands: Challenges, operational strategies and overall performance. Environ. Pollut. 201, 107-120. doi:10.1016/j.envpol.2015.03.006

567 Wu, W., 2007. Computational River Dynamics. CRC Press.

568 Yang, L., Tsai, K.-Y., 2011. Treatment of landfill leachate with high levels of ammonia by constructed wetland systems. J. Environ. Sci. Heal. 46, 736-741.

570 doi:10.1080/10934529.2011.571586 